\title{
Switching and energy-storage characteristics in PLZT 2/95/5 antiferroelectric ceramic system
}

\author{
A. Peláiz-Barranco* ${ }^{\S}$, Y. Mendez-González*, J. D. S. Guerra ${ }^{\dagger}$, Xiucai Wang* \\ and Tongqing Yang* \\ *Facultad de Física - IMRE, Universidad de La Habana \\ San Lázaro y L, Vedado, La Habana 10400, Cuba \\ ${ }^{\dagger}$ Grupo de Ferroelétricos e Materiais Multifuncionais, Instituto de Física \\ Universidade Federal de Uberlândia, 38408-100, Uberlândia - MG, Brazil \\ * Functional Materials Research Laboratory, College for Materials Science and \\ Engineering, Tongji University, 4800 Caoan, Shanghai 201804, P. R. China \\ pelaiz@fisica.uh.cu
}

Received 18 August 2016; Revised 27 October 2016; Accepted 31 October 2016; Published 23 November 2016

\begin{abstract}
Switching mechanisms and energy-storage properties have been investigated in $\left(\mathrm{Pb}_{0.98} \mathrm{La}_{0.02}\right)\left(\mathrm{Zr}_{0.95} \mathrm{Ti}_{0.05}\right)_{0.995} \mathrm{O}_{3}$ antiferroelectric ceramics. The electric field dependence of polarization ( $P-E$ hysteresis loops) indicates that both the ferroelectric (FE) and antiferroelectric (AFE) phases coexist, being the AFE more stable above $100^{\circ} \mathrm{C}$. It has been observed that the temperature has an important influence on the switching parameters. On the other hand, the energy-storage density, which has been calculated from the $P-E$ hysteresis loops, shows values higher than $1 \mathrm{~J} / \mathrm{cm}^{3}$ for temperatures above $100^{\circ} \mathrm{C}$ with around $73 \%$ of efficiency as average. These properties indicate that the studied ceramic system reveals as a promising AFE material for energy-storage devices application.
\end{abstract}

Keywords: Antiferroelectrics; energy-storage; switching.

\section{Introduction}

Nowadays, because of the increasing levels in the global air pollution, the energy deficiency and the visible changes in the environment conditions, new energy generation technologies, such as solar, wind and thermal energies, are being developed in order to replace the fossil fuel energy resources with cleaner renewable energy sources. Such new technologies in turn lead to a high demand of new devices for effectively storing, absorbing, and supplying the electricity.

From the technological point of view, it is known that conventional dielectric capacitors have high power density but their energy density is low, which limits their potential for specific applications. ${ }^{1}$ In this way, the exploration to improve the energy-storage density in such devices has received special attention in the last years, thus promoting the development of a new devices generation based on compact electronic and electrical systems, light weight and high integration levels, toward the miniaturization. For a proper material to be used in energy-storage devices, three requirements have to be simultaneously satisfied: (i) high breakdown electric field, (ii) large saturation polarization and (iii) small remnant polarization. ${ }^{1}$

Typical linear dielectrics (LD) usually exhibit high breakdown electric field and low energy losses. However, their small polarization values make them nonsuitable materials for high energy-storage applications. On the other hand, the ferroelectric (FE) systems, which are classical nonlinear dielectrics (NLD), show often large saturation polarization values as well as moderate electric-field endurance. Nevertheless, the high remnant polarization values in these cases lead to a small energy-storage density and low efficiency. In this context, the antiferroelectric (AFE) systems seems to be appropriate materials to be used for high energy-storage devices, because of their large saturation polarization values, small remnant polarization and moderate breakdown electric field. The AFE systems, which are characterized by doublelike hysteresis loops, possess electric dipoles with antiparallel ordering, so that no macroscopic polarization can arise. However, in the presence of an electric field, an AFE state can be transformed into a FE state, storing large amounts of electrical energy due to the sudden increase in the polarization. $^{2}$

Lead-based ceramics, such as lead zirconate $(\mathrm{PZ})^{2,3}$ and modified lead zirconate titanate (PZT), for specific compositions, ${ }^{4-12}$ have been recognized up today as the most important AFE systems ever reported in the current literature. Furthermore, it has been evaluated for some systems, that the doping by using $\mathrm{La}^{3+}$ ions generally promotes the stability of the AFE phase over the FE phase..$^{8-12}$

This is an Open Access article published by World Scientific Publishing Company. It is distributed under the terms of the Creative Commons Attribution 4.0 (CC-BY) License. Further distribution of this work is permitted, provided the original work is properly cited. 
Recent progress in the investigation on the physical properties of $\left(\mathrm{Pb}_{1-x} \mathrm{La}_{x}\right)\left(\mathrm{Zr}_{0.95} \mathrm{Ti}_{0.05}\right)_{1-x / 4} \mathrm{O}_{3}$ ceramic system, ${ }^{13}$ revealed interesting behavior in the electric field dependence of polarization ( $P-E$ hysteresis loops) at different temperatures, for compositions containing 2 at $\%$ of lanthanum. Results have shown that an AFE phase is stable over the FE phase in a wide temperature range, even for temperatures near the Curie temperature. The present paper aims to study the characteristics of the $P-E$ hysteresis loops in order to determine the influence of the applied electric field and temperature on the phase switching features. The energystorage characteristics have been also investigated and discussed, viewing to evaluate the potential of the studied ceramics for high energy-storage applications.

\section{Experimental Procedure}

$\left(\mathrm{Pb}_{0.98} \mathrm{La}_{0.02}\right)\left(\mathrm{Zr}_{0.95} \mathrm{Ti}_{0.05}\right)_{0.995} \mathrm{O}_{3}$ [PLZT 2/95/5] ceramic system was prepared by the traditional solid-sate reaction method. High purity chemical precursors such as $\mathrm{PbO}$ (99.9\%, Alfa Aesar), $\mathrm{TiO}_{2}$ (99.9\%, Johnson Matthey), $\mathrm{ZrO}_{2}$ (99\%, Merck) and $\mathrm{La}_{2} \mathrm{O}_{3}$ (99.99\%, Alfa Aesar) were used as starting powders. The mixed oxides were milled for $2 \mathrm{~h}$, then dried and pressed in uniaxial press under $1 \mathrm{ton} / \mathrm{cm}^{2}$ of pressure. The mixture was calcined at $800^{\circ} \mathrm{C}$ for $1 \mathrm{~h}$ in air atmosphere. The powders were milled again for $1 \mathrm{~h}$, dried and pressed $\left(2 \mathrm{ton} / \mathrm{cm}^{2}\right)$. The samples were then sintered in a closed platinum crucible at $1250^{\circ} \mathrm{C}$ for $1 \mathrm{~h}$, in air atmosphere. Ceramic samples with high density were obtained $\left(\rho=6.9 \mathrm{~g} / \mathrm{cm}^{3}\right)$.

Silver painted-electrodes were applied on the parallel surfaces of the disk-shaped samples by a heat treatment at $590^{\circ} \mathrm{C}$. The hysteresis loops $(P-E$ curves $)$ measurements were performed at $10 \mathrm{~Hz}$ and several temperatures by using a FE analyzer (Premium II, Radiant Technologies Inc.), which is combined with a high voltage power source (TReK Model 663A).

\section{Results and Discussion}

Figure 1 shows the hysteresis loops for the studied system at several temperatures. Typical hysteresis loops for AFE behavior are observed, which indeed is more evident for temperatures above $100^{\circ} \mathrm{C}$. Nonlinearities in the $P-E$ behavior were evident from room temperature; however saturation was not achieved until temperatures above $100^{\circ} \mathrm{C}$ where the phase switching from AFE to FE states can clearly be seen.

Figure 2 shows the temperature dependence of the backward switching electric field $\left(E_{\mathrm{FE}-\mathrm{AFE}}\right)$, the forward switching electric field $\left(E_{\mathrm{AFE}-\mathrm{FE}}\right)$ and the hysteresis loop width [ $\left.\Delta E=\left(E_{\mathrm{AFE}-\mathrm{FE}}-E_{\mathrm{FE}-\mathrm{AFE}}\right)\right]$, which have been obtained from Fig. 1. The $E_{\mathrm{FE}-\mathrm{AFE}}$ is the electric field at which the FEAFE transition occurs, while $E_{\mathrm{AFE}-\mathrm{FE}}$ is the electric field which forces the AFE to FE transition to occurs, respectively.

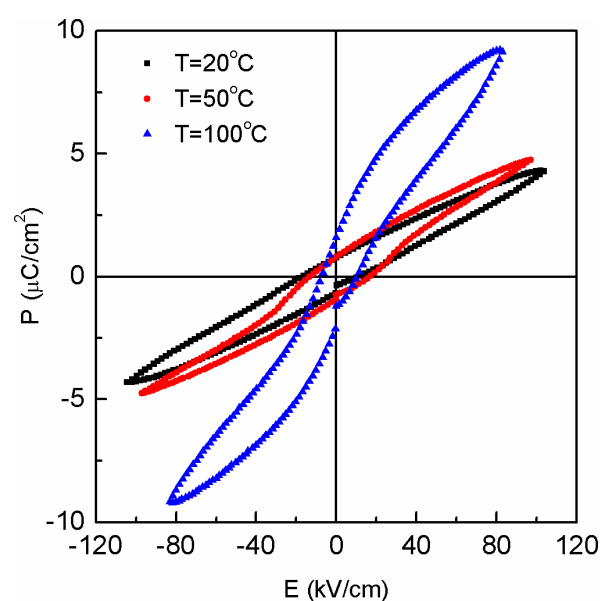

(a)

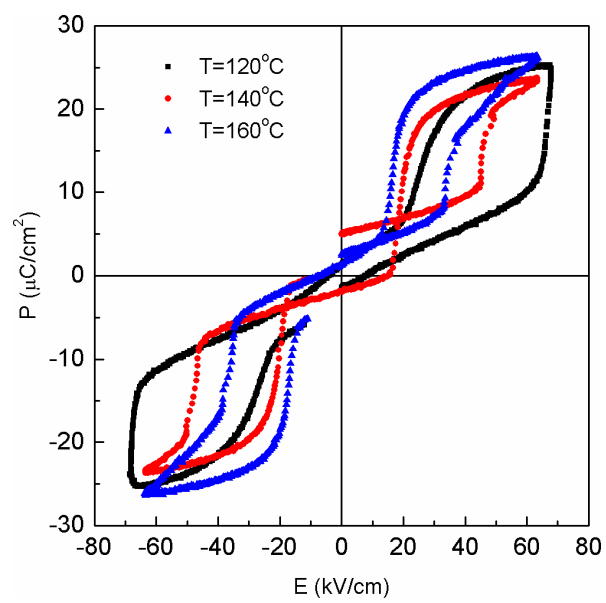

(b)

Fig. 1. Hysteresis loops for several temperatures.

For simplicity, $E_{\mathrm{AFE}-\mathrm{FE}}$ has been taken as the electric field that promotes the increase of the polarization up to half of its maximum value. At the same time, the $E_{\mathrm{FE}-\mathrm{AFE}}$ has been considered as the electric field that promotes the decrease of the polarization up to half of its maximum value. It is important to point out that, this analysis have been only considered for temperatures above $100^{\circ} \mathrm{C}$ because for lower temperatures a higher electric field must be applied in order to obtain the real switching electric field values, as observed in Fig. 1.

Both the backward switching field $\left(E_{\mathrm{FE}-\mathrm{AFE}}\right)$ and the forward switching field $\left(E_{\mathrm{AFE}-\mathrm{FE}}\right)$ decrease with the increase of the temperature (Fig. 2). The observed behavior results in a decrease in the electric hysteresis width $(\Delta E)$, which could be valuable for applications in nonlinear capacitors. The influence of the temperature on these parameters, and then on the relative stabilities of the FE and AFE phases, has been reported in the literature for Sn-modified PZT system, ${ }^{14}$ where a FE-AFE phase transformation has been observed on heating. On the other hand, previous reports on PLZT 2/95/5 


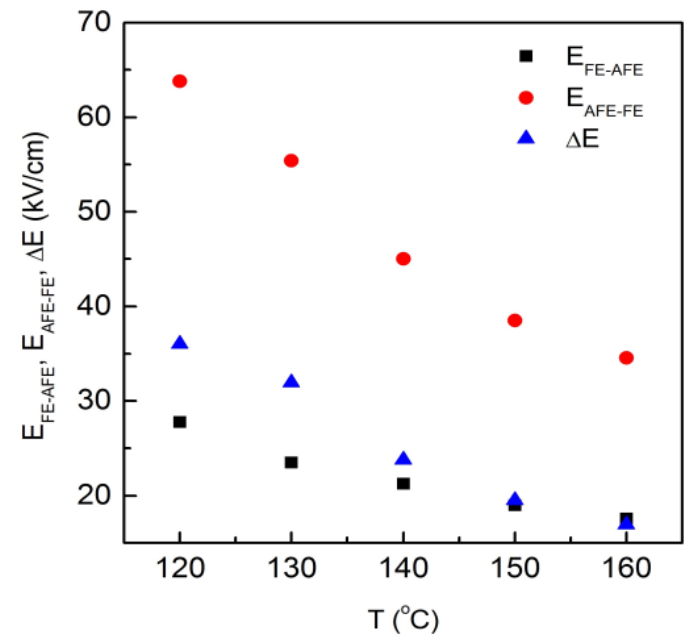

Fig. 2. Temperature dependence of the switching parameters.

have also shown that the FE and AFE phases could coexist over certain ranges of temperatures and an AFE-AFE phase transition can take place around $120^{\circ} \mathrm{C}$, being the $\mathrm{AFE}$ one for temperatures higher than $120^{\circ} \mathrm{C}$ an incommensurate state $\left(\mathrm{AFE}_{\text {in }}\right) .{ }^{13,15-17}$

The electric field, $E_{\mathrm{AFE}-\mathrm{FE}}$, which is required to induce the transformation from AFE to FE phase, can be written as $E_{\mathrm{AFE}-\mathrm{FE}}=E_{0}-\Delta E_{\mathrm{AFE}-\mathrm{FE}}$, where $E_{0}$ is the intrinsic nonhysteretic term and $\Delta E_{\mathrm{AFE}-\mathrm{FE}}$ is the hysteretic term. ${ }^{18} \mathrm{Sim}$ ilar analysis can be made for the $E_{\mathrm{FE}-\mathrm{AFE}}$ electric field $\left(E_{\mathrm{FE}-\mathrm{AFE}}=E_{0}-\Delta E_{\mathrm{FE}-\mathrm{AFE}}\right)$, where $E_{0}$ and $\Delta E_{\mathrm{FE}-\mathrm{AFE}}$ are nonhysteretic and hysteretic terms, respectively. The hysteresis width $\Delta E$ is the sum of both hysteretic terms, ${ }^{18}$ $\Delta E=\Delta E_{\mathrm{AFE}-\mathrm{FE}}+\Delta E_{\mathrm{FE}-\mathrm{AFE}}$.

A thermodynamic approach developed by Yang and Payne $^{18}$ has shown that the $E_{0}$ parameter depends on the difference between both the free energy for the FE state and that for the AFE one, while $\Delta E_{\mathrm{AFE}-\mathrm{FE}}$ and $\Delta E_{\mathrm{FE}-\mathrm{AFE}}$ are related to the energy barriers for the transformations from AFE to FE or from FE to AFE states, respectively. $E_{0}$ should increase with temperature, moving out itself from the point where the free energies of the FE and AFE phases are the same. However, the effects of the temperature on $\Delta E_{\mathrm{AFE}-\mathrm{FE}}$ and $\Delta E_{\mathrm{FE}-\mathrm{AFE}}$ are different. There was a noticeable decrease of $\Delta E$ with the increase of the temperature (Fig. 2), indicating that both $\Delta E_{\mathrm{AFE}-\mathrm{FE}}$ and $\Delta E_{\mathrm{FE}-\mathrm{AFE}}$ parameters decreased suddenly at higher temperatures. Then, the decrease in the $\Delta E_{\mathrm{AFE}-\mathrm{FE}}$ and $\Delta E_{\mathrm{FE}-\mathrm{AFE}}$ hysteretic terms, with the increase of temperature, is responsible for the observed decrease in the $E_{\mathrm{AFE}-\mathrm{FE}}$ and $E_{\mathrm{FE}-\mathrm{AFE}}$ electric fields.

Table 1 shows the recoverable electrical energy density $\left(J_{R}\right)$ and the energy-storage efficiency $(\eta)$ for the studied ceramic. The energy-storage efficiency can be calculated by using Eq. (1), where $J_{L}$ is the electrical loss energy density. ${ }^{1}$

$$
\eta=\frac{J_{R}}{J_{R}+J_{L}} .
$$

Table 1. Recoverable electrical energy density $\left(J_{R}\right)$ and the energy-storage efficiency $(\eta)$ for several temperatures.

\begin{tabular}{lcc}
\hline$T\left({ }^{\circ} \mathrm{C}\right)$ & $J_{R}\left(\mathrm{~J} / \mathrm{cm}^{3}\right)$ & $\eta(\%)$ \\
\hline 20 & 0.357 & 80 \\
50 & 0.379 & 82 \\
75 & 0.426 & 80 \\
100 & 0.376 & 65 \\
110 & 1.089 & 69 \\
120 & 1.045 & 60 \\
130 & 1.250 & 79 \\
140 & 1.234 & 78 \\
150 & 1.147 & 77 \\
160 & 1.220 & 75 \\
\hline
\end{tabular}

The results show lower $J_{R}$ values around room temperature than those reported for other similar AFE materials based on PZT. ${ }^{19}$ The studied system requires higher applied electric fields in order to reach saturation for $T \leq 100^{\circ} \mathrm{C}$. Even when nonlinearities in the $P-E$ behavior were evident from room temperature, the polarization saturation region was not achieved until temperatures above $100^{\circ} \mathrm{C}$. Only when the applied electric field increases beyond the switching electric fields, the polarization saturation region takes place and higher $J_{R}$ could be achieved.

On the other hand, the obtained $J_{R}$ values are higher than those reported for typical $\mathrm{PbZrO}_{3}$ AFE ceramics ${ }^{20}$ and similar to the values reported for PLZT thick films. ${ }^{21}$ The observed results suggest the studied system as potential AFE ceramics for application in energy-storage devices.

It is important to note that when the temperature increases above $100^{\circ} \mathrm{C}$, higher values of $J_{R}$ are achieved, with about $73 \%$ of efficiency as average in the $110-160^{\circ} \mathrm{C}$ temperature range. This is, in fact, the temperature range where the AFE phase is more stable. Similar studies in lead-free AFE systems have shown lower $J_{R}$ values in the stable AFE phase region. ${ }^{22,23}$

\section{Summary}

As summary, $\left(\mathrm{Pb}_{0.98} \mathrm{La}_{0.02}\right)\left(\mathrm{Zr}_{0.95} \mathrm{Ti}_{0.05}\right)_{0.995} \mathrm{O}_{3}$ AFE ceramic system has been studied under high electric fields. The characteristics of the hysteresis loops and the switching properties have been discussed considering a wide temperature range. The results indicate that the FE and AFE phases coexist, being the AFE more stable above $100^{\circ} \mathrm{C}$. The backward switching field $E_{\mathrm{FE}-\mathrm{AFE}}$ and the forward switching field $E_{\mathrm{AFE}-\mathrm{FE}}$ showed a decrease with the increase of temperature. It has been also observed that the electric hysteresis width $\Delta E$ decreases with the increase of the temperature. This result can be related to the coexistence of both the AFE and FE phases. On the other hand, the energy-storage characteristics have been also analyzed showing values higher than $1 \mathrm{~J} / \mathrm{cm}^{3}$ in the stable AFE region, with around $73 \%$ of 
energy efficiency as average. These properties indicate that the studied ceramic system might be a promising material for energy-storage capacitor applications.

\section{Acknowledgments}

The authors would like to acknowledge the Third World Academy of Sciences (RG/PHYS/LA Nos. 99-050, 02-225 and 05-043), and the ICTP, Trieste-Italy, for financial support of Latin-American Network of Ferroelectric Materials (NET43). Thanks to CNPq and FAPEMIG Brazilian agencies for financial support. Dr. Peláiz-Barranco would like to thank Tongji University (Shanghai, China) for financial support. MSc. Mendez-González thank ICTP-CLAF for financial support of the $\mathrm{PhD}$ fellowship.

\section{References}

${ }^{1}$ N. H. Fletcher, A. D. Hilton and B. W. Ricketts, Optimization of energy storage density in ceramic capacitors, J. Phys. D: Appl. Phys. 29, 253 (1996).

${ }^{2} \mathrm{X}$. Hao, A review on the dielectric materials for high energystorage application, J. Adv. Dielect. 3, 1330001 (2013).

${ }^{3}$ A. S. Mischenko, Q. Zhang, J. F. Scott, R. W. Whatmore and N. D. Mathur, Giant electrocaloric effect in thin film $\mathrm{PbZr}_{0.95} \mathrm{Ti}_{0.05} \mathrm{O}_{3}$, Science 311, 1270 (2006).

${ }^{4}$ H. Zhang, X. Chen, F. Cao, G. Wang, X. Dong, Z. Hu and T. Du, Charge-discharge properties of an antiferroelectric ceramics capacitor under different electric fields, J. Am. Ceram. Soc. 93, 4015 (2010).

${ }^{5}$ X. Chen, F. Cao, H. Zhang, G. Yu, G. Wang, X. Dong, Y. Gu, $\mathrm{H}$. He and Y. Liu, Dynamic hysteresis and scaling behavior of energy density in $\mathrm{Pb}_{0.99} \mathrm{Nb}_{0.02}\left[\left(\mathrm{Zr}_{0.60} \mathrm{Sn}_{0.40}\right)_{0.95} \mathrm{Ti}_{0.05}\right] \mathrm{O}_{3}$ antiferroelectric bulk ceramics, J. Am. Ceram. Soc. 95, 1163 (2012). ${ }^{6}$ S. E. Young, J. Y. Zhang, W. Hong and X. Tan, Mechanical selfconfinement to enhance energy storage density of antiferroelectric capacitors, J. Appl. Phys. 113, 054101 (2013).

${ }^{7}$ X. Hao, Y. Wang, L. Zhang, L. Zhang and S. An, Compositiondependent dielectric and energy-storage properties of $(\mathrm{Pb}, \mathrm{La})(\mathrm{Zr}$, $\mathrm{Sn}, \mathrm{Ti}) \mathrm{O}_{3}$ antiferroelectric thick films, Appl. Phys. Lett. 102, 163903 (2013).

${ }^{8}$ Z. Xu, X. H. Dai and D. Viehland, Impurity-induced incommensuration in antiferroelectric La-modififed lead zirconate titanate, Phys. Rev. B 51, 6261 (1995).

${ }^{9}$ Z. Xu, X. H. Dai, J.-F. Li and D. Viehland, Coexistence of incommensurate antiferroelectric and relaxor-like orderings in Lamodified high $\mathrm{Zr}$-content lead zirconate titanate, Appl. Phys. Lett. 68, 1628 (1996).

${ }^{10}$ A. Peláiz-Barranco, J. D. S. Guerra, O. García-Zaldívar, F. Calderón-Piñar, E. B. Araújo, D. A. Hall, M. E. Mendoza and
J. A. Eiras, Effects of lanthanum modification on dielectric properties of $\mathrm{Pb}\left(\mathrm{Zr}_{0.90}, \mathrm{Ti}_{0.10}\right) \mathrm{O}_{3}$ ceramics: Enhanced antiferroelectric stability, J. Mater. Sci. 43, 6087 (2008).

${ }^{11}$ J. Knudsen, D. I. Woodward and I. M. Reaney, Domain variance and superstructure across the antiferroelectric/ferroelectric phase boundary in $\mathrm{Pb}_{1-1.5_{x}} \mathrm{La}_{x}\left(\mathrm{Zr}_{0.9} \mathrm{Ti}_{0.1}\right) \mathrm{O}_{3}$, J. Mater. Res. 18, 262 (2003).

${ }^{12}$ A. Peláiz-Barranco and D. A. Hall, Influence of composition and pressure on the electric field-induced antiferroelectric to ferroelectric phase transformations in lanthanum modified lead zirconate titanate ceramics, IEEE Trans. Ultrason. Ferroelectr. Freq. Control 56(9), 1785 (2009).

${ }^{13}$ Y. Mendez-González, A. Peláiz-Barranco, A. Pentón Madrigal, J. D. S. Guerra, G. Jie, W. Xiucai and T. Yang, Effects of the lanthanum concentration on the $\left(\mathrm{Pb}_{1-x} \mathrm{La}_{\mathrm{x}}\right)\left(\mathrm{Zr}_{0.95} \mathrm{Ti}_{0.05}\right)_{1-x / 4} \mathrm{O}_{3}$ antiferroelectric ceramic system, Rev. Cub. Fis. 33, 12 (2016).

${ }^{14}$ D. Berlincourt, H. Jaffe, H. H. A. Kreuger and B. Jaffe, Release of electric energy in $\mathrm{PbNb}(\mathrm{Zr}, \mathrm{Ti}, \mathrm{Sn}) \mathrm{O}_{3}$ by temperature- and by pressure-enforced phase transitions, Appl. Phys. Lett. 3, 90 (1963).

${ }^{15}$ D. Viehland, X. H. Dai, J. F. Li and Z. Xu, Effects of quenched disorder on La-modified lead zirconate titanate: Long- and short range ordered structurally incommensurate phases, and glassy polar clusters, J. Appl. Phys. 84, 458 (1998).

${ }^{16}$ D. Viehland, J.-F. Li, X. Dai and Z. Xu, Structural and property studies of high zr-content lead zirconate titanate, J. Phys. Chem. Solids 57, 1545 (1996).

${ }^{17}$ X. Daí and D. Viehland, Effects of lanthanum modification on the antiferroelectric-ferroelectric stability of high zirconium-content lead zirconate titanate, J. Appl. Phys. 76, 3701 (1994).

${ }^{18} \mathrm{P}$. Yang and D. A. Payne, Thermal stability of field-forced and field-assisted antiferroelectric-ferroelectric phase transformations in $\mathrm{Pb}(\mathrm{Zr}, \mathrm{Sn}, \mathrm{Ti}) \mathrm{O}_{3}$, J. Appl. Phys. 71, 1361 (1992).

${ }^{19}$ J. Wang, T. Yang, S. Chen and X. Yao, Small hysteresis and high energy storage power of antiferroelectric ceramics, Funct. Mater. Lett. 7(1), 1350064 (2014).

${ }^{20} \mathrm{~K}$. Singh, Antiferroelectric lead zirconate, a material for energy storage, Ferroelectrics 94, 433 (1989).

${ }^{21} \mathrm{X}$. Hao, P. Wang, X. Zhang and J. Xu, Microstructure and energystorage performance of $\mathrm{PbO}-\mathrm{B}_{2} \mathrm{O}_{3}-\mathrm{SiO}_{2}-\mathrm{ZnO}$ glass added $\left(\mathrm{Pb}_{0.97} \mathrm{La}_{0.02}\right)\left(\mathrm{Zr}_{0.97} \mathrm{Ti}_{0.03}\right) \mathrm{O}_{3}$ antiferroelectric thick films, Mater. Res. Bull. 48, 84 (2013).

${ }^{22}$ G. Viola, H. Ning, M. J. Reece, R. Wilson, T. M. Correia, P. Weaver, M. G. Cain and H. Yan, Reversibility in electric fieldinduced transitions and energy storage properties of bismuthbased perovskite ceramics, J. Phys. D: Appl. Phys. 45, 355302 (2012).

${ }^{23}$ F. Gao, X. Dong, C. Mao, W. Liu, H. Zhang, L. Yang, F. Cao and G. Wang, Energy-storage properties of $0.89 \mathrm{Bi}_{0.5} \mathrm{Na}_{0.5} \mathrm{TiO}_{3}-$ $0.06 \mathrm{BaTiO}_{3}-0.05 \mathrm{~K}_{0.5} \mathrm{Na}_{0.5} \mathrm{NbO}_{3}$ lead-free anti-ferroelectric ceramics, J. Am. Ceram. Soc. 94, 4382 (2011). 